\title{
Da condição vestigial em Aquele Grande Rio Eufrates de Ruy Belo
}

\author{
About vestigial condition in Aquele Grande Rio Eufrates de Ruy Belo
}

\author{
FRANCISCO SARAIVA FINO ${ }^{1}$ \\ ${ }^{1}$ CEL - Universidade de Évora. Évora, Portugal.
}

Resumo: Este ensaio propõe uma leitura da primeira obra poética de Ruy Belo (1933-1978), Aquele Grande Rio Eufrates, publicada em 1961 e seguida onze anos depois da segunda edição, já com alterações assinaláveis, a partir de três termoschave que anuncia no prefácio que redigiu em 1972: a solidão do sujeito, a cidade e, como enquadramento privilegiado dos anteriores, a reflexão sobre o tempo, presente neste livro em versões como as de crise ou quotidiano. A partir destes tópicos e de exemplos de poemas da obra referida, procura-se neste trabalho a indagação da importância dos sinais ou vestigia da memória transportada pela palavra poética e de que modo a atitude de avistamento desses residua por parte do sujeito lírico permite sustentar as tensões entre as representações do real e o seu processo criativo.

Palavras-chave: tempo; cidade; solidão; crise; quotidiano; palavra.

\begin{abstract}
This essay proposes a reading of the first poetic work of Ruy Belo (19331978), Aquele Grande Rio Eufrates, published in 1961 and with a new edition eleven years later with notable changes. This critical reading will be made upon three key terms that the poet announces in the preface written in 1972: the solitude of the subject, the city and, as a privileged context of the previous ones, the reflection on the time, showed in this book as some versions like those of crisis or everyday life. From these topics and critical readings of poems of Aquele Grande Rio Eufrates, we will search, in this study, the inquiry of the importance of signs or memory vestigia carried on by poetic word and in what way the attitude of sighting these residua allows lyrical subject to sustain the tensions between representations of reality and its own creative process.
\end{abstract}

Keywords: time; city; solitude; crisis; everyday life; word. 
A escolha do tema deste ensaio muito deve, como ponto de partida, ao imprescindível posfácio que Joaquim Manuel Magalhães compôs para o primeiro volume da Obra Poética de Ruy Belo (1981), de cuja leitura retivemos uma expressão em particular, "resíduos oraculares" (apud BELO, 1984, p. 217). No contexto referido, surge a propósito de dois objetos concretos, dois bilhetes de autocarro que Joaquim Manuel Magalhães dava como "esquecidos" numa edição anotada pelo autor do seu primeiro livro, Aquele Grande Rio Eufrates (AGRE). O posfaciador atribuía a essa invenção ocasional um significado particular, a capacidade de evocar, através destes dois vestígios, a ideia detransporte como núcleo temático dominante na sua poesia. Ao fazê-lo, conectou metaforicamente (e entendemos aqui a metáfora na sua particularidade etimológica de transferência ou transporte) dois fragmentos de "real quotidiano" tornadas memória entre as páginas do livro e outra importante metáfora no contexto do universo poético de Ruy Belo, o da deambulação ou movimento das coisas e do ser em processo de busca do que poderíamos afirmar como o seu reencontro ou avistamento no tempo. Nesse acontecimento e em que medida com ele poderá comunicar a condição vestigial sugerida no título desta comunicação consistirá o essencial desta apresentação, partindo da primeira obra poética de Ruy Belo que, conforme também Joaquim Manuel Magalhães fizera notar, "em sua vida permanecera em sombra uma luz difícil e encantatória" (apud BELO, 1984, p. 217).

De facto, a própria ideia de movimento como mudança de estado viria a afetar Aquele Grande Rio Eufrates enquanto objeto-livro, se tivermos em consideração as diferenças conhecidas entre a primeira e a segunda edição, permitindo-nos lê-las do ponto de vista dessa "qualidade transumante da sua escrita" que o posfaciador igualmente entendeu destacar. Por sua vez, é importante não esquecer que, entre 1961 e 1972, data da segunda edição, o poeta contaria, além de AGRE, com três títulos de poesia publicados (O Problema da Habitação, 1962; Boca Bilingue, 1966; Homem de Palavra(s), 1970), além do volume crítico Na Senda da Poesia (1969), de algumas traduções e ainda de todas as autoconfessadas leituras de obras e autores agrupadas sob a designação de "influências", testemunhos da sua unanimemente considerada adesão ao sentido eliotiano de uma modernidade sustentada na escuta e diálogo permanente com a tradição. No transporte entre as duas edições há que contar, por conseguinte, com substancial lastro cujas dimensões e peso, talvez não predeterminados, como no prefácio da segunda edição alega a propósito da mudança e da ausência de predeterminação nas coisas da sua vida (BELO, 2014, p. 16), nunca haveriam de deixar de importar no momento em que acabaria por nela proceder a "modificações muito mais profundas e numerosas do que alguma vez pensara introduzir" (BELO, 2014, p. 16).

A afirmação anterior vale uma leitura atenta: a par das modificações mais visíveis que explicita, como a supressão das maiúsculas (a mais célebre seria a da palavra 'Deus') e a redução da pontuação, há, de facto, a vontade em atribuir significado à importância dessas mudanças, que procura fornecer aos leitores enquanto claros sinais de diferença e mesmo de progresso para a reflexão metapoética, de que julgamos 
indício suficiente a referência à substituição da epígrafe inicial da primeira edição, retirada do Tratado de Pintura de Leonardo Da Vinci, pela da segunda, colhida em Citadelle, obra de Antoine de SaintExupéry que traduzira e viria publicada (com o sucesso de reedições nos anos seguintes) em 1968, empreendimento que, por si só, mereceria um estudo mais atento no âmbito das relações intertextuais com AGRE. A mencionada "outra ordem de ideias" para essa substituição enquadrava-se na perceção de que "afinal a poesia é, ao fim e ao cabo, uma aventura de linguagem, por muito que os significantes possam significar" (BELO, 2014, p.19). Aventura que não dispensou, no caso de AGRE, o fundamental do texto-base da primeira edição, apesar do que nos afirma o poeta e de todas as alterações recensadas por Joaquim Manuel Magalhães no final da Obra Poética, as quais acabam por corroborar a conclusão da não exclusão de qualquer poema, pese as breves alterações em dois deles e, apesar disso, mantendo os títulos da edição de 1961. Esse núcleo original, tornado residuum ou 'aquilo que fica no fundo', 'o que permanece sentado' (de sedere), o que 'subsiste' ou o que 'dura', vem a constituir, em relação à segunda edição, a memória sempre presente de uma aventura da linguagem feita movimento, transporte ou, como veremos, encontro de vestígios de um poderoso fundo cuja permanência acompanha a errância do sujeito num percurso feito de avistamentos e distanciamentos, entre a meditação sobre o tempo e o lugar, entre o quotidiano e a palavra poética. Sob estes tópicos conduziremos, pois, o essencial das nossas próximas indagações.

A "modificação mais profunda" entre as edições cabe, de facto, à criação do prefácio que, como lemos, considerara "indispensável antepor a esta segunda edição" (BELO, 2014, p.15). Subtraindo-nos de, neste trabalho, desenvolver a sua natureza simultaneamente irónica e metapoética (difíceis que são as fronteiras, neste objeto, entre um e outro domínio), optamos por nele perscrutar e confirmar a permanência própria do residuum na forma da expressão daquilo que em diferentes passos o próprio autor sistematiza como momento crítico e ao qual associa o contexto compositivo dos poemas. Citamos três excertos do prefácio da segunda edição, ilustrativos dessa reflexão: o primeiro,

Apesar disso sofri alguma coisa, numa sociedade e num país onde se sofre muito. No termo de dez anos de uma aventura mística que terminou há dez anos, eu saí para a rua e para o diaa-dia com este punhado de poemas, com estas palavras que me consentiram escrever nos breves intervalos de um silêncio durante muitos anos imposto, a pretexto de que, de contrário, a minha alma correria perigo, como se eu tivesse uma coisa como alma, como se correr perigo não fosse talvez a mais profunda razão de vida (BELO, 2014, p. 16-17).

Passamos para a segunda citação: "Quem tiver tempo e paciência para isso, não deixará talvez de notar que, à data da composição destes poemas, atravessava uma crise profunda quem aliás sempre viveu em crise, apesar de, nos domínios fundamentais, ter porventura por conta própria arriscado mais que muitos homens de sistema, de ideologia, de doutrina, de instituição" (BELO, 2014, p.17); por último, "Todo este livro foi escrito num clima a que não só já não tenho acesso hoje em dia como espero não o voltar a ter" (BELO, 2014, p. 19). A presença do 
vocábulo 'crise'ou a alusão ao contexto crítico como fundamento ontológico do ato criativo permite-nos, desde modo, integrá-lo nessa multiplicidade significativa que tenderia a assumir na modernidade a reocupação de um termo (krisis) cuja presença entre os Gregos, onde terá primeiramente surgido, conhecera desde cedo ampla plurissignificação. Para Reinhardt Koselleck (cf. KOSELLECK, 2006, p.358), este conceito alcançaria a época moderna enquanto importante termo de análise existencial em domínios como a psicologia e a teologia, conservando em si, entre outros, sentidos que recebera da medicina de tradição hipocrática que haviainfluentemente relacionado a krisis com um sentido particular de tempo em rápida mudança, governado pela expetativa e pela necessidade de juízos adequados sobre circunstâncias de exceção. Em The Sense of an Ending, Frank Kermode acentuou a natureza eminentemente ontológica da crise quando a apresenta como uma forma de cada um pensar o seu próprio momento, não sendo ela inerente ao próprio momento (cf. KERMODE, 1997, p. 104). Regressando às palavras de Ruy Belo e colocando de parte as circunstâncias pessoais de composição dos poemas, sobejamente conhecidas e de resto aludidas no prefácio, importará nelas destacar a expressão desse pensar sobre uma "vida sempre em crise", para o qual aponta um juízo relevante: "tema limite dessa crise talvez seja o da solidão no meio da cidade" (BELO, 2014, p. 17).

Neste último período em concreto concentram-se, de facto, dois dos tópicos privilegiados na sua poesia, o da solidão do homem e o da cidade, perfeitamente interligados e comuns a outras experiências literárias da Modernidade (Baudelaire,
António Nobre ou Fernando Pessoa serão disso exemplo), e que em Aquele Grande Rio Eufrates principiam a sua caminhada entre a produção poética de Ruy Belo. Um terceiro tópico, o do tempo na sua versão crítica, dominará em nosso entender os restantes, de acordo, de resto, com a visibilidade assegurada pelo título da obra e a sua fonte bíblica, o livro da Revelação ou Apocalipse, por sua vez diretamente evocado na forma de epígrafes - na do último poema homónimo ou na epígrafe da "Ode do homem de pé" (cf. BELO, 2014 p. 114), esta acrescentada na segunda edição - assim como pelos sinais que nos introduzem no seu imaginário mais corrente, como "Escatologia" (cf. BELO, 2014, p. 71), "Advento do anjo" (cf. BELO, 2014, p. 94), ou "Maran atha" (cf. BELO, 2014, p. 57), o primeiro da série "Tempo" e expressão de remate do apocalipse joanino (em aramaico, a exortação "Vem, Senhor"). Há, porém, a esclarecer, entre a abundante complexidade da aceção de "apocalipse", em que modalidade temporal nos devemos situar nestes poemas, considerando que o apocalipse tanto poderá remeter para o tempo messiânico (o da promessa, o do advento da Jerusalém Celeste) como para o tempo escatológico, entendido enquanto fim ou consumação do próprio tempo. Convocamos com esse intuito os esclarecimentos que Giorgio Agamben nos presta em/l tempo che resta. Un commento alla Lettera ai Romani (2000) quanto às diferenças entre o tempo do profeta e o do apóstolo: se para o primeiro existe uma relação estreita com o futuro, com um tempo ainda a vir e com o fim do tempo, já o segundo está interessado no tempo do fim, aquele que principia a acabar ou, citando, "o tempo que resta entre o tempo e o seu final" (AGAMBEN, 2005, p. 62). 
É precisamente esse intervalo que parece servir de objeto meditativo em AGRE, conduzindo a errância do sujeito no quotidiano segundo a expetativa segura da solidão da morte conforme lemos em alguns versos de "Saudades de melquise de que" (BELO, 2014, p. 59):

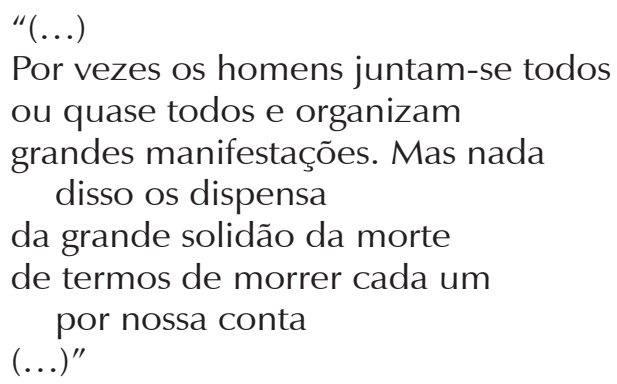

Num horizonte em que a transcendência, já sem o consolo ou o temor providenciados por esse Deus maiusculado do ponto de vista da crença religiosa, se revela ao homem pela linguagem poética, a morte assume-se a convivência do quotidiano com a aceitação do inelutável no tempo que resta como nos é afirmado com alguma ironia no dístico final de "As duas mortes": "Cada dia mais morte que morte / haverá para nós no fim dos dias?" (BELO, 2014, p. 90). Na cidade terrena do homem de que ele é, segundo o poema "Mors semper prae oculis" (emblema de todas as vanitates artísticas), "dos edifícios da cidade / um dos que há-de ruir amanhã" (BELO, 2014, p. 73), nenhum outro encontro lhe será proporcionado com maior certeza no final das suas deambulações pelo "Espaço preenchido", título do poema onde também podemos ler: "abrem-se-nos ruas /para ir a sítios demasiado precisos / quando um só sítio se encontra / ao fim de todas as ruas e de todos os rios" (BELO, 2014, p. 78).

Ocorre-nos aqui uma outra conclusão de Frank Kermode que vem confirmar a posição já invocada de Agamben quanto ao nascimento do moderno conceito de crise a partir dos textos de São Paulo e de São João, os quais, ao distanciarem-se do sentido iminente de Fim presente em São Marcos, próprio do eschaton, procuram acentuar o Fim como imanente ao homem e o presente como "o tempo entre o momento de cada um e a sua morte" (KERMODE, 1997, p. 40). Nesse intervalo deve, por conseguinte, situar o homem a sua atenção ao quotidiano, outro termo que na poética de Ruy Belo merece grande destaque e que a crítica tem vindo desde sempre a privilegiar. É necessário recordar, todavia, o modo como esse quotidiano - $\mathrm{e}$ cingimo-nos apenas à obra que nos orienta neste estudo - se transfigura em dispositivo de representação do tempo imanente que procura caracterizar a representação do "momento de cada um" e de acordo com o qual a expressão da referencialidade do acontecimento diário concreto se vai intercalando (como acontece no último poema de AGRE) e convertendo à expressão do tempo ontológico. Esse processo culminará no longo poema final, homónimo do título global da obra, e que a ensaísta Rosa Maria Martelo salientou como um dos primeiros sinais de recorrência do discurso da alegoria neste género de composição e interpretando-o como "um dispositivo de montagem textual que assenta na recolha obsessiva de recordações fragmentárias" sem que, prosseguindo na citação, seja possível "estabelecer coordenadas espácio-temporais estáveis" (MARTELO, 2015, p. 121).

Recuperamos duas importantes referências ao termo "quotidiano" em Aquele Grande Rio Eufrates, a primeira na quintilha "O percurso diário" (BELO, 2014, p. 100): 
Eu vou por este sol além e ele é quotidiano até ao fim como se até hoje ninguém tivesse no sol e fora do sol também morrido a morte por mim

Já a segunda, no "Poema quotidiano", retoma a ideia da composição anterior na imagem do Sol, "ele que ninguém habitualmente saudava", prestando "eficiente serviço", todavia apenas reconhecido pelos habitantes do bairro no momento da sua morte - "Mas hoje o sol / morreu como qualquer um de nós / Ficou tão triste a gente destes sítios / Nunca foi tão depressa noite neste bairro" (BELO, 2014, p. 109). A perceção da finitude prolonga-se na distensão do intervalo ao evocar a permanência do homem face ao desaparecimento de uma segura coordenada de tempo quotidiano, o da ação ou trabalho humano. Revelado o "Astro-rei", conforme é também referido no poema, como um desses "pobres seres transitórios" (expressão que lemos no poema "Homeoptoto"), a sua potencial fragilidade é apenas aparente quando sabemos que é do lado humano (contingente) que se exprime o sentimento de perda e não do lado do elemento natural. Na série anterior, dedicada ao tempo, compreendêramos já em "A história de um dia" o modo ambivalente como esses efeitos afetam o sol e o sujeito; se, no primeiro caso, todos o viram "partir pontualmente à mesma hora" mas para "abrir outras portas / erguer verticalmente caídas esperanças / e passar novas mãos por tantas faces mortas" (BELO, 2014, p.69), a perda da luz assinala poeticamente a perda da capacidade de soltar "a palavra definitiva", cessando esse trabalho de "arredondar / uma íntima ampola de som" (BELO, 2014, p. 69). À maneira de Alberto
Caeiro, de quem recolhe o vestígio de um famoso verso, o sujeito-poeta entende que só the "resta recolher o seu rebanho de pensamentos", sendo que neles, como afirma, "morre irremediavelmente" ou, mais adiante, "morro mais uma vez criticamente completo" (BELO, 2014, p.69). Não se tratando de uma perda definitiva, ela marca, porém, a diferença entre o astro e o sujeito e, dentro da ciclicidade que o poema expõe, entre a permanência e a alteridade: "Amanhã serei outro", como escreve, ocupando a "arrumada paisagem quotidiana" (BELO, 2014, p. 70), destinado à errância e à recomposição dos pensamentos, porventura recorrendo aos restos das anteriores atividades transumantes.

O fim de um dia é o recomeço de outro dia, ou de outro fim. Conforme nos é dado a ler ainda a partir do poema anterior, "Assim sou passado de dia em dia / confiado pelo dia que parte ao dia que chega" (BELO, 2014, p.70). O quotidiano continuará arrumado na sua mudança periódica, ao contrário do sujeito enunciador que deverá recomeçar a nova busca pela palavra definitiva, partindo dos pensamentos que anteriormente "estendia", "recolhia" e "orientava numa direção que convinha / e os precipitava sobre o fumo de uma casa / sobre um buraco de luz ou uma coluna de fumo / mais volúveis que um bando de pássaros"(BELO, 2014, p.69). A imagem da atividade do respigador, aquele que recolhe os restos das colheitas, confirmase no verso "de ventre ferido na aventura do restolho" e introduz significativamente a ideia do labor do gesto e a vivência de "vinte e quatro horas de história" debruçado sobre os vestígios deixados pelos dias.

"Todo o caminho é de regresso", lemos ainda em "A história de um dia" 
(BELO, 2014, p.69), verso que conduz a nossa reflexão a uma das topografias privilegiadas (não sendo a única, o que de resto o mesmo poema demonstra) de Aquele Grande Rio Eufrates, a cidade, o outro membro do tema limite da crise enunciado no prefácio. Já o entrevíramos a propósito dos dois primeiros poemas citados sobre o quotidiano, inseridos na secção "A cidade", testemunhos da sua importância na expressão da errância dos dias. Com o propósito de melhor as desenvolvermos, convocamos Michel de Certeau, para quem, o ato de caminhar é a consequência de ter falta de lugar e o processo indefinido de estar ausente e à procura de um próprio. Podemos lê-lo em L'invention du quotidiende que convocamos o excerto que se segue:

A errância, multiplicada e reunida pela cidade, faz dela uma imensa experiência social de privação de lugar uma experiência, é verdade, esfarelada em deportações inumeráveis e ínfimas (deslocamentos e caminhadas), compensadas pelas relações e cruzamentos desses êxodos que se entrelaçam, criando um tecido urbano, e posta sob o signo que deveria ser, enfim, o lugar, mas é apenas um nome, a Cidade (CERTEAU, 1994, p. 183).

Concentremo-nos no último período da citação de modo a esclarecer como poderá a experiência do lugar e da errância suscitar em Aquele Grande Rio Eufrates a configuração do nome 'Cidade'. As aceções presentes nos poemas são, também em relação a este tópico, múltiplas; no poema "Metamorfose", ela torna-se lugar de passagem, avistamento ou cruzamento, neste último caso com a figura (a imagem) de si mesmo: "ó homem que tens à espera de ti /virada a esquina da rua e do tempo o teu próprio rosto" (BELO, 2014, p. 32); já em "Epígrafe para a nossa solidão", a meditação sobre a morte prossegue nos versos do poema anterior para albergar a comunidade humana, o fundamento da polis, dentro da mesma expetativa ontológica: "Cruzámos nossos olhos em alguma esquina / demos civicamente os bons dias: / chamar-nosão vais ver contemporâneos"(BELO, 2014, p. 77). Entre estes avistamentos, porém, o mais significativo será porventura o de Deus, que em "Vestigia dei" se converte em transeunte na comparação que lemos nos versos "És sempre como aquele que encontramos / diariamente pela rua fora / e a pouco e pouco vemos onde mora" (BELO, 2014, p. 43). Trata-se de uma presença que, tal como a de todos os que caminham pelas ruas, se vai tornando reconhecível, passando a ocupar um lugar na memória do outro e cuja profundidade aumenta quando compreendemos do lado do sujeito a perceção de que esse avistamento é bidirecional. Afinal, como é afirmado no primeiro verso de "Teoria da presença" (na segunda edição, "Teoria da presença de deus"), "Somos seres olhados" (BELO, 2014, p. 82) e no poema "Vestigia dei" esse olhar-memória, feito dos vestígios perscrutados na palavra, encontra-se associado à atividade criadora do poeta - "Não assistisses tu a esta nossa vida / caíssem-nos os gestos ou quebrados ou dispersos / e nenhum rosto decisivo um dia fecharia / todas as palavras com que dissemos os versos" (BELO, 2014, p. 44). A importância dos sinais ou vestigia de Deus assume-se do ponto de vista da memória transportada pela palavra poética que, por sua vez, se encontra adstrita ao avistamento do sujeito-poeta, capaz de nomear e de nomear deus. Leia-se o 
poema "Quanto morre um homem" e a hipótese de o objeto nele apresentado se reportar a Deus - "Quem dará o teu nome a todas as ruas / que encontrar no coração e na cidade?" e "Quando toda a alegria for clandestina / alguém te dobrará em cada esquina?" (BELO, 2014, p. 72). A necessidade do homem, da sua solidão e da sua mortalidade, para a nomeação de deus e de todas as coisas ou mesmo para a nomeação (acrescentaríamos, o "avistamento") de si mesmo além do transitório legitima a primazia da universalidade da palavra poética, ainda que, como parte dessa transitoriedade, também ela esteja ferida de morte. Em Na Senda da Poesia (1969), numa das partes do ensaio "Poesia Nova", anterior em redação à primeira edição de AGRE, podemos ler: "Mas apesar de tudo, a palavra poética é a mais expressiva, a mais transitória, a mais concreta de todas as palavras universais. É uma palavra de encruzilhada" (BELO, 2002, p. 70). Deste modo, ela faz parte e é a Cidade, na medida em que concreto e abstrato se desencontram e se avistam nas suas ruas e esquinas numa geometria em permanente edificação e destruição. $\mathrm{O}$ mesmo ensaio prossegue: "É memória de um caso humano. É ela própria o conteúdo vivo. Luta contra o tempo, vence-o, e não obstante, a cada passo morre. Não há quem a reconheça, quem a identifique na sua antiga estirpe. Tem de ser purificada. É abstrata, dita depois de muita experiência, e existe singularmente, com o vigor de uma única vez" (BELO, 2002, p. 70). Como palavra, como antiga estirpe, experiência singular e memória, Deus e a sua história não escapam às grelhas geométricas desta Cidade, pelo que também elas são evidentemente convocadas, avistadas e sujeitas às contingências do transporte no tempo. A esperança da poesia, no avistar dos antigos sinais ou pegadas materiais das ocupações anteriores, é a de garantir que o projeto da eternidade (de que deus também faz parte) se possa restaurar (ainda que irremediavelmente ferido pela contingência da existência transitória) entre as coisas concretas. Citando a importante conclusão de Manuel Gusmão em Tatuagem \& Palimpsesto, elas são "coisas de um mundo finito que a poesia pode entretanto ilimitar sem, para tal, precisar de transpor uma transcendência originária ou essencial" (GUSMÃO, 2010, p. 416).

Ainda no regime da temporalidade, importa-nos recordar a importante lição de Agostinho de Hipona nas Confissões, segundo o qual, quanto aos acontecimentos passados, a memória relata não os próprios acontecimentos que já decorreram mas "as palavras concebidas pelas imagens daqueles factos, os quais, ao passarem pelos sentidos, gravaram no espírito uma espécie de vestígios" (AGOSTINHO, 1999, p. 284). O tempo presente entende-se como o da memória e não o passado, no qual os acontecimentos já não são; o exemplo dado por Agostinho neste trecho é o da infância, época que, quando tomada como objeto de descrição e os seus vestígios são evocados pela memória, acaba por se ver no presente. Daí que, também nesta obra e pela palavra poética, a Cidade urja em se converter em experiência vestigial que potencie nas encruzilhadas das memórias disponíveis atos de reconhecimento e de compreensão, presentificando-os. Sendo a Cidade a palavra poética nas suas encruzilhadas, entenderemos, com Michel de Certeau, em que medida ela possa constituir "uma rede de estadas tomadas de empréstimo por uma circulação, uma agitação através 
das aparências do próprio, um universo de locações frequentadas por um não-lugar ou por lugares sonhados" (CERTEAU, 1994, p. 183). A leitura da penúltima secção de AGRE oferece-nos, tal como as restantes, alguns exemplos desses empréstimos de circulação na forma de "resíduos oraculares" ou alicerces (aquilo que, lembremos, fica em fundo), memórias pertinazes dos tempos das ocupações sagradas de nãolugares (pensemos, por exemplo, na Cidade de Deus de Agostinho de Hipona, obra nascida em ambiente de crise), ou, em evidente correlação, de lugares tornados sonhos ou utopias como é o caso de Babel, a grande cidade da ruína do projeto divino da língua única, situada precisamente nas margens "daquele grande rio Eufrates", ou, ainda mais expressivamente, Jerusalém, nas suas augustininas versões terrena leia-se "Jerusalém, jerusalém... ou alto da serafina" (BELO, 2014, p. 112) - ou celeste, a que é "grande" e que ainda mantém em si "o espaço de um domingo" (o dia do Senhor), conforme se expõe em "Fundação de roma" (BELO, 2014, p. 97), possível poema-síntese da alegoria augustiniana das duas cidades, a dos homens e a de Deus, a primeira representada na Fundação de Roma (herdeira do crime de Caim) com o ato criminoso de Rómulo, a segunda, a Jerusalém celeste, para a qual se dirige todo o peregrinar "com o gládio do espírito" com o intuito de "rasgar à sua volta um areal de silêncio / onde o sol ilumine os cristais dos meus dias" (BELO, 2014, p.97).

"A verdade meu deus é a cidade / que nasce onde e porque os teus / olhos e os meus após chorar se olharam" (BELO, 2014, p.123), como lemos no longo poema final da obra, "Aquele grande rio eufrates", a narração da epopeia da palavra poética, compreendendo nestes versos que também esta, no transporte dos resíduos originais, necessita da voz do poeta para assumir o seu significado translatício. Essa exigência, no entanto, sublinha a sua condição crítica no sentido em que a sua responsabilidade não se funda somente na restituição, partindo da palavra prática, da memória da sua primitiva origem poética, porquanto também é afirmado no estudo citado de Na Senda da Poesia que, "se essa memória se perde, só um poeta descobrirá nela uma vitalidade originária, restituindo-a ao seu primeiro latejo ou inventando-a radicalmente no sentimento e na fantasia" (BELO, 2002, p. 64). Daí que se compreenda, a partir da leitura do poema "Perigo de vida", como "É grande o risco da palavra no tempo" ou mesmo "Tivesse ela lábios e não seria / tão grave o risco no tempo e no mar" (BELO, 2014, p. 80); no entanto, e em simultâneo, os poemas oferecem os meios que possibilitam a restituição "ao primeiro latejo", entre os quais figuram os sucessivos encontros e "avistamentos" colhidos em cada encruzilhada e cujos vestígios poderemos ainda surpreender em AGRE no modo como a memória adere ao "transporte no tempo" e como cada poema se abre à pluralidadede leituras.

\section{Referências}

AGOSTINHO DE HIPONA. Confissões, 13. ed. Trad. Lúcio Craveiro da Silva, S.J. e Elias Couto. Braga: Livraria Apostolado da Imprensa, 1999.

AGAMBEN, Giorgio. The time that remains - a commentary on the letter to the Romans. Trad. Patricia Dailey. Stanford: Stanford University Press, 2005.

BELO, Ruy. Obra Poética, vol. 1. Organização e posfácio de Joaquim Manuel Magalhães. 2. ed. Lisboa: Editorial Presença, 1984.

BELO, Ruy. Na Senda da Poesia. Lisboa: Assírio \& Alvim, 2002.

BELO, Ruy. Todos os Poemas. 2. ed. Lisboa: Assírio \& Alvim, 2014. 
CERTEAU, Michel de. A Invenção do Cotidiano: 1. Artes de fazer. Trad. Ephraim Ferreira Alves. Petrópolis: Vozes, 1994.

GUSMÃO, Manuel. Tatuagem \& Palimpsesto - da poesia em alguns poetas e poemas. Lisboa: Assírio \& Alvim, 2010.

KERMODE, Frank. A Sensibilidade Apocalíptica. Trad. Melo Furtado. Lisboa: Edições Século XXI, 1997.

KOSELLECK, Reinhardt. Crisis. Trad. Michaela Richter. In: Journal of the History of Ideas, v. 67, n. 2, p. 357-400, Apr. 2006.

MARTELO, Rosa Maria. Alegoria, fragmento e montagem nos poemas longos de Ruy Belo.
In: ATHAYDE, Manaíra Aires (Org.). Literatura Explicativa. Lisboa: Assírio \& Alvim, 2015. p.111126.

Recebido: 21 de novembro de 2018

Aceito: 18 de novembro de 2018

FRANCISCO SARAIVA FINO

Licenciado em Línguas e Literaturas Modernas pela Faculdade de Letras da Universidade do Porto (Portugal). Mestre em Criações Literárias Contemporâneas pela Universidade de Évora (Portugal). Doutorando em Literatura Portuguesa pela Universidade de Évora. Investigador do CEL - Centro de Estudos em Letras da Universidade de Évora. Membro das Comissões de Espólio e de Edição da obra do poeta Daniel Faria.

(D) http://orcid.org/0000-0002-9781-438X <fmsfino@gmail.com> 